South Dakota State University

Open PRAIRIE: Open Public Research Access Institutional

Repository and Information Exchange

Agronomy, Horticulture and Plant Science

Department of Agronomy, Horticulture, and

Faculty Publications

Plant Science

$6-2016$

Physiological and Molecular Characterisation of Lucerne

(Medicago sativa L.) Germplasm with Improved Seedling Freezing

Tolerance

M. Rokebul Anowar

Anne Fennell

Arvid Boe

Ivan W. Mott

Michael D. Peel

See next page for additional authors

Follow this and additional works at: https://openprairie.sdstate.edu/plant_faculty_pubs

Part of the Agronomy and Crop Sciences Commons 
Authors

M. Rokebul Anowar, Anne Fennell, Arvid Boe, Ivan W. Mott, Michael D. Peel, and Yajun Wu 


\title{
Physiological and molecular characterisation of lucerne (Medicago sativa L.) germplasm with improved seedling freezing tolerance
}

\author{
M. Rokebul Anower ${ }^{\mathrm{A}}$, Anne Fennell ${ }^{\mathrm{B}}$, Arvid Boe ${ }^{\mathrm{B}}$, Ivan W. Mott ${ }^{\mathrm{C}}$, Michael D. Peel ${ }^{\mathrm{C}}$, \\ and Yajun $W u^{\mathrm{A}, \mathrm{D}}$ \\ A Department of Biology and Microbiology, South Dakota State University, Brookings, SD 57007, USA. \\ ${ }^{B}$ Department of Plant Science, South Dakota State University, Brookings, SD 57007, USA. \\ ${ }^{C}$ USDA-ARS Forage and Range Research Lab, Utah State University, Logan, UT 84322, USA. \\ ${ }^{D}$ Corresponding author. Email: yajun.wu@sdstate.edu
}

\begin{abstract}
We conducted greenhouse experiments to compare 14 lucerne (alfalfa, Medicago sativa L.) germplasms for their survival following freezing. Some are collections adapted to the Grand River National Grasslands in South Dakota. We hypothesised that these collections might have developed a tolerance to survive the frigid growth conditions common there. Two of these collections, River side (RS) and Foster ranch (FR), showed greater freezing tolerance than the other germplasms tested, based on their consistent survival rates with or without cold acclimation. In multiple freezing studies, RS and FR had average survival rates of $74 \%$ and $79 \%$, respectively, in contrast to the commercial cultivars Apica and CUF-101 (CUF) (64\% and 24\%, respectively). The average temperature at which 50\% of ions in plant tissues leak out $\left(\mathrm{LT}_{50}\right)$ by freezing based on leaf electrolyte leakage was closely correlated with survival rates. Leaf $\mathrm{LT}_{50}$ improved 2-3fold after 3 days of cold acclimation, based on leaf electrolyte leakage analysis, reaching $-18^{\circ} \mathrm{C},-9.6^{\circ} \mathrm{C},-8.5^{\circ} \mathrm{C}$, and $-5^{\circ} \mathrm{C}$ for RS, FR, Apica, and CUF, respectively. Comparison of total soluble sugars and relative water content in shoots before and after cold acclimation showed that they were not well correlated with freezing tolerance and could not explain the superior responses of RS and FR during cold acclimation. Transcript analysis of cold-responsive $M s C B F 1, M s C B F 2$ and $C A S 15 B$ genes showed that RS, FR, Apica and CUF exhibited distinct patterns of cold induction. Although RS, FR and Apica showed a rapid or greater increase in expression level of one or two of these genes, CUF showed only a moderate induction in $M S C B F 2$ and $C A S 15 B$ transcripts, suggesting that expression of these genes may be a good molecular marker for freezing tolerance in lucerne. The findings provide evidence that freezing tolerance in lucerne is a complex trait and that a combination of different mechanisms may greatly improve freezing tolerance. RS and FR are potential resources in breeding for improving freezing tolerance in lucerne.
\end{abstract}

Additional keyword: gene expression.

Received 23 June 2015, accepted 28 January 2016, published online 28 June 2016

\section{Introduction}

Lucerne (also known as alfalfa, Medicago sativa L.) is a major forage legume grown extensively worldwide, with important agronomic and environmental attributes (Castonguay et al. 2009; Anower et al. 2013). Lack of quick acclimation to cold and lack of freezing tolerance are major constraints to lucerne production in northern cold regions (Brouwer et al. 2000; Castonguay et al. 2015; Rocher et al. 2015). A large percentage of the lucerne hay in the United States is produced in the Midwestern states of South Dakota, North Dakota, Minnesota, Iowa and Wisconsin, and the cultivars are typically highly autumn-dormant to survive freezing temperatures in winter (Sheaffer et al. 1997). Although selection of autumn-dormant varieties is important for lucerne production in these areas with harsh winters, establishment and successful survival through the first winter after seeding can be critical for production because rapid drop in temperature occurs frequently in early autumn or late spring. Thus, it is also important to develop germplasm with improved freezing tolerance. Of course, an overall greater freezing tolerance in lucerne will improve its persistence in climates of the Midwest and northern United States.

Most temperate plant species increase freezing tolerance after exposure to progressive, non-freezing low temperature, a phenomenon known as cold acclimation (Thomashow 1999; Castonguay et al. 2006). Studies have shown that prior exposure to cold acclimation increases lucerne freezing tolerance many-fold (Mohapatra et al. 1989; Monroy and Dhindsa 1995; Chen et al. 2015; Lizhen et al. 2015). Other studies with plants such as Arabidopsis have demonstrated that the ability to survive winter is dependent on the rate of cold acclimation and 
the ultimate level and stability of acclimation (Thomashow 2001; Chinnusamy et al. 2007; Zuther et al. 2015). Numerous physiological changes occur during exposure to low temperature, and some of them are believed to be important to freezing tolerance. For instance, organ-specific compatible solute or osmolyte accumulation prevents plants from experiencing sudden osmotic shock. Freezing stress directly inhibits cellular metabolic activities and reduces water uptake, thus inducing cellular dehydration or osmotic stress (Chinnusamy et al. 2007; Arias et al. 2015). Solutes accumulated in plants under lowtemperature stress include amino acids such as proline, glutamine, methionine, arginine and histidine, and soluble sugars such as sucrose, glucose, fructose, melibiose, xylose, mannitol, sorbitol, trehalose, raffinose and stachyose. These solutes accumulate in the crown, taproots and leaves of lowtemperature-stressed lucerne plants (Castonguay et al. 2006; Tarkowski and Van den Ende 2015; Zhang et al. 2015; Zuther et al. 2015). In addition to reducing water loss, a high accumulation of these solutes prevents ice formation and helps to stabilise macromolecules and membrane integrity in freezinginduced desiccation (Levitt 1980; Anchordoguy et al. 1987; Duca 2015). Low-temperature and freezing stress, furthermore, causes enhanced metabolite flux and oxidative load on tissues, and the resulting reactive oxygen species (ROS) are one of the major hindrances to plant growth (Farooq et al. 2009). Thus, antioxidant defence or cellular-damage repair mechanisms through antifreeze protein-dehydrins are equally important for freezing tolerance (Thomashow 1998; Chinnusamy et al. 2007).

Many of these physiological and biochemical responses are a consequence of altered gene expression regulated by a complex genetic network. Differential expression of protein and RNA has been associated with genetic differences in cold acclimation and freezing tolerance (Guy 1990; Castonguay et al. 2006). Numerous studies show that a diversity of coldregulated $(C O R)$ or responsive genes are involved in plant freezing tolerance (Monroy et al. 1993; Jaglo-Ottosen et al. 1998; Thomashow 1998; Park et al. 2015; Zhao et al. 2015). However, only limited success in improving freezing tolerance has been achieved by manipulating just single genes, because multiple genes are likely act in concert to increase freezing tolerance. In Arabidopsis, a key molecular process leading to cold acclimation and improved freezing tolerance is the C-repeat binding factor (CBF) response pathway. Recent work has showed that $\mathrm{CBF}$ regulon genes and other cold-responsive genes are regulated by a complex network that involves many early cold-induced transcription factors (Park et al. 2015; Zhao et al. 2015). CBFs are activators of many downstream genes, which collectively act to increase freezing tolerance (Fowler and Thomashow 2002; Maruyama et al. 2004; Park et al. 2015). Among the genes upregulated by CBF3 are those encoding synthesis of cryoprotective polypeptides and soluble sugars (Gilmour et al. 2000). Pennycooke et al. (2008) compared Medicago truncatula and lucerne subsp. falcata for their capacity to acclimate to cold and demonstrated the highly inducible nature of $C B F$ transcript levels. Cas15, a coldinduced dehydrin gene in lucerne, showed parallel changes in transcript levels and freezing tolerance (Monroy et al. 1993; Lizhen et al. 2015). Dehydrins comprise a complex gene family and are potentially important for preventing freeze- induced cellular dehydration. Dubé et al. (2013) searched within a library of cold-induced cDNA in lucerne and discovered two novel K3-dehydrin gene variants that were linked with superior freezing tolerance and cold adaptation. However, other genes involved in cold tolerance in lucerne are largely unknown.

Screening of lucerne germplasm for freezing tolerance has been practiced for a long time (McKenzie et al. 1988; Schwab et al. 1996b; Castonguay et al. 2009). Despite considerable effort, conventional breeding methods have met with only modest improvements in freezing tolerance. Castonguay et al. (2009) successfully identified lucerne with improved freezing tolerance through greenhouse screening of mature plants based on regrowth after freezing stress. Forage scientists and plant physiologists have often used the electrolyte leakage method to evaluate freezing injury (Burr et al. 1990; Mattsson 1997). Electrolyte-leakage analysis through electric conductivity measurement appears to be a useful tool to estimate the average lethal temperature at which $50 \%$ of the plants survive the freezing treatment $\left(\mathrm{LT}_{50}\right)$ (Burr et al. 1990; Thomashow 1999; Thapa et al. 2008). Consequently, a simple determination of the tissue-specific $\mathrm{LT}_{50}$ can be considered a reasonably reliable reflection of winter hardiness of lucerne. In fact, the electrolyteleakage-based method has been used to select lucerne with improved freezing tolerance (Sulc et al. 1991; McKersie et al. 1996; Thapa et al. 2008).

In this study, we used freezing survival in combination with a leaf electrolyte-leakage assay to evaluate freezing tolerance of 14 lucerne accessions and cultivars. Some of the accessions tested in this study were naturalised lucerne collected from the Grand River National Grassland of semi-arid or subhumid rangeland in South Dakota where unpredictable freezing occurs frequently in autumn and spring. We hypothesised that freezing tolerance in some of the naturalised accessions of lucerne is superior to that of other germplasm sources because they should be adapted to the relatively sudden drops in temperature.

\section{Materials and methods}

\section{Plant materials}

Fourteen lucerne germplasms including accessions and cultivars were examined in this study (see Supplementary materials, table S1, available at the journal's website). They included River side (RS), Foster ranch (FR), Wind River, Alfagraze, CHBB-04, BCBB-04, MT-01, A-1991, SD-201, DON, CUF-101 (CUF; freezing-sensitive), Ameristand 47 TQ, Apica (freezing-tolerant) and Caribou (freezing-tolerant). Seeds of RS were collected from the Grand River National Grassland $\left(45^{\circ} \mathrm{N}, 102^{\circ} \mathrm{W}\right), \mathrm{SD}$, and seeds of FR collected from Thunder Butte Creek $\left(45^{\circ} \mathrm{N}, 101 \mathrm{~W}^{\circ}\right)$, north of Faith, SD. Wind River, a variegated lucerne, was collected from the Norman 'Bud' Smith Ranch, Lodgepole, SD, and seeds of MT-01 were collected from a rangeland population near Outlook, MT, USA. BCBB-04, CHBB-04 and A-201 are breeding populations from the USDA-ARS Forage and Range Research Laboratory, Logan, UT, USA. Don is a pure falcata cultivar developed by Dr Michael Peel, USDA-ARS, Logan, UT, and SD-201 is another falcata cultivar, developed by Dr Arvid Boe at South Dakota State University. Seeds of CUF and Ameristand 407 TQ were 
provided by the National Temperate Forage Legume Genetic Resource Unit, Prosser, WA, USA. Seeds of Apica and Caribou were generously provided by Dr Yves Castonguay (AAFC, Canada).

\section{Plant culture}

Seeds were scarified with 3M 332U 150 aluminium oxide general-purpose sandpaper (3M, Maplewood, MN, USA) and then sterilised in $2.5 \%$ bleach solution for $3 \mathrm{~min}$. After three thorough washes with distilled water, the seeds were soaked in distilled water overnight at $4^{\circ} \mathrm{C}$. The following day, seeds were transferred to wet filter paper (Whatman No. 1; Whatman International, Maidstone, UK) in a Petri dish and germinated at $25^{\circ} \mathrm{C}$ in the dark for 6 days. Seedlings were transplanted into Ray Leach Cone-tainers (Stuewe \& Sons, Corvallis, OR, USA), $3.8 \mathrm{~cm}$ by $21 \mathrm{~cm}$, two seedlings each, and filled with $38 \mathrm{~g}$ potting mix (Sunshine Mix \#3; Sun Gro Horticulture Canada, Seba Beach, AB, Canada). Plants were grown in a greenhouse at a thermo-period of $24^{\circ} \mathrm{C}$ (day) and $18^{\circ} \mathrm{C}$ (night), with a $16-\mathrm{h}$ photoperiod. Supplemental lighting from 1000-W metal halide lamps was used to provide $\sim 350 \mu \mathrm{mol} \mathrm{m}^{-2} \mathrm{~s}^{-1}$ of photosynthetically active radiation (PAR) at soil level. Plants were irrigated at 3-day intervals with a Miracle-Gro (Scotts Miracle-Gro Products, Marysville, OH, USA) nutrient solution (5 g Miracle-Gro per gallon (3.79 L) $\mathrm{H}_{2} \mathrm{O} ; \mathrm{N}: \mathrm{P}: \mathrm{K}, 15: 30: 15$ ). On day 10 after transplanting, seedlings were thinned to one plant per cone.

\section{Freezing test}

Freezing tolerance of whole plants was evaluated as described by Pennycooke et al. (2008), with some modifications. Plants grown in a greenhouse were used for freezing tests with or without cold acclimation. For cold acclimation before a freezing test, plants $(\sim 3$ weeks of age) were transferred to a $2^{\circ} \mathrm{C}$ growth chamber with 16 -h photoperiod, at a light intensity of $200 \mu \mathrm{mol} \mathrm{m}^{-2} \mathrm{~s}^{-1}$ of PAR, and kept for 2-7 days depending on experiments. The cold-acclimated and non-acclimated plants were transferred to a freezing chamber (thermal shock test chamber; Tenney, New Columbia, PA, USA) after nucleation with ice. The freeze tests were conducted by reducing the temperature from $4^{\circ} \mathrm{C}$ to $-2^{\circ} \mathrm{C}$ over $30 \mathrm{~min}$ and holding at $-2^{\circ} \mathrm{C}$ for $8 \mathrm{~h}$. The temperature was then decreased by $1^{\circ} \mathrm{C}$ per $\mathrm{h}$ to a target temperature and held for $90 \mathrm{~min}$. After freezing, plants were placed overnight in a dark cold-room at $4^{\circ} \mathrm{C}$. Plants were then moved to the greenhouse, at $24^{\circ} \mathrm{C}$, for growth recovery. Survival was scored as the proportion of plants that had resumed growth 10 days after freezing treatment. Freezingtolerant Apica and Caribou were included as positive controls and the sensitive CUF as a negative control. Plants that survived the freezing treatment were grown in the greenhouse for 3 weeks (de-acclimation) and were subjected to freezing stress again as described above. Six plants per replication of each germplasm type were used for each freezing test, and each test was repeated four times.

\section{Electrolyte leakage}

Tissue-specific $\mathrm{LT}_{50}$ values were determined to estimate the temperature at which the leaf and stem tissues showed $50 \%$ ion leakage, using the modified method of Thapa et al. (2008).
The temperatures tested were: $-1,-2,-3,-4,-5$, and $-6^{\circ} \mathrm{C}$ (nonacclimated leaf); $-1,-3,-5,-8,-10$, and $-12^{\circ} \mathrm{C}$ (non-acclimated shoot); $-3,-6,-9,-12,-15$ and $-18^{\circ} \mathrm{C}$ (after 3 days of coldacclimation); $-3,-6,-9,-12,-15,-18$ and $-24^{\circ} \mathrm{C}$ (after 7 days of cold-acclimation). For each test temperature, two leaves of similar age were sampled from each of three replicate plants for six replications in total and were placed in test tubes. Six nonfreezing-treated samples were placed on ice in the tubes as controls. The tubes containing frost-treated samples were placed in a glycol bath at $-1^{\circ} \mathrm{C}$ for $1 \mathrm{~h}$, after which freezing was initiated by ice-nucleation produced by dropping a small ice crystal into each tube and maintaining at $-1^{\circ} \mathrm{C}$ for $1 \mathrm{~h}$ before further lowering the temperature. The temperature in the glycol bath was lowered by $1^{\circ} \mathrm{C}$ per $\mathrm{h}$, and frozen subsamples were removed at each test temperature and thawed on ice overnight. On the following day, the samples were removed from ice and kept at $4^{\circ} \mathrm{C}$ for $2 \mathrm{~h}$ and at room temperature for another $1 \mathrm{~h}$. After adding $20 \mathrm{~mL}$ deionised water to each tube, the samples were placed on a gyratory platform shaker (Innova-2000; New Brunswick Scientific, Edison, NJ, USA) at 150 r.p.m. overnight. An initial ion-leakage measurement was taken with a conductivity meter (Model 2052; VWR, Atlanta, GA). Samples were then autoclaved at $121^{\circ} \mathrm{C}$ for $30 \mathrm{~min}$ with a slow exhaust cycle of $0.45 \mathrm{~kg} \mathrm{~min}^{-1}$. After the samples were brought to room temperature, the total ion leakage was measured. Percentage of injury was calculated by using the formula described by Thapa et al. (2008). $\mathrm{LT}_{50}$ values were used to separate germplasms for their relative differences in freezing tolerance.

\section{Relative water content}

Samples were weighed immediately after harvest to determine fresh weight (FW) and then submerged in deionised water for $48 \mathrm{~h}$ at $4^{\circ} \mathrm{C}$ in the dark. The samples were weighed again for turgid fresh weight (TFW) after the plant tissues were blotted dry. The tissues were vacuum-dried for 3 days at $40^{\circ} \mathrm{C}$ and weighed to obtain dry weight (DW). Relative water content (RWC) was calculated as described in Barrs and Weatherley (1962) by using the equation:

$$
\mathrm{RWC}(\%)=[(\mathrm{FW}-\mathrm{DW}) /(\mathrm{TFW}-\mathrm{DW})] \times 100
$$

\section{Sugar measurement}

For sugar extraction, root and shoot tissues were ground in liquid nitrogen to a fine powder, $20 \mathrm{mg}$ of which was mixed with $400 \mu \mathrm{L}$ double-deionised water in a $1.5-\mathrm{mL}$ centrifuge tube (Thermo Fisher Scientific, Waltham, MA, USA), using a vortex mixer. The mixture was centrifuged at 12000 r.p.m. for $5 \mathrm{~min}$ at $4^{\circ} \mathrm{C}$. The supernatant was heated at $100^{\circ} \mathrm{C}$ for $10 \mathrm{~min}$ and afterwards centrifuged at 12000 r.p.m. for $5 \mathrm{~min}$ at $4^{\circ} \mathrm{C}$. After centrifugation, the supernatant containing the total soluble sugars was transferred to a new centrifuge tube.

Supernatant $(5 \mu \mathrm{L})$ was incubated with $40 \mu \mathrm{L}$ anthrone reagent $(2 \mathrm{~g}$ anthrone dissolved in $100 \mathrm{~mL}$ concentrated $\mathrm{H}_{2} \mathrm{SO}_{4}$ ) in a boiling water bath in a Corning Costa 96-well flat-bottom plate (Sigma-Aldrich, St. Louis, MO, USA) for $10 \mathrm{~min}$ in the dark. The absorbance of the products was detected by Synergy HT microplate reader and spectrometer 
(BioTek, Winooski, VT, USA) at $620 \mathrm{~nm}$ and quantified using Gen5 Analysis software based on a standard curve constructed by using known concentrations of D-glucose (Thermo Fisher Scientific).

\section{RNA extraction and CDNA synthesis}

To understand the molecular basis of the difference in freezing tolerance, we studied the expression of a small set of coldresponsive genes in FR and RS compared with cold-tolerant Apica and cold-sensitive CUF cultivars. Plants were subjected to $2^{\circ} \mathrm{C}$ for 0,2 and $24 \mathrm{~h}$, and young shoots were harvested for RNA extraction and transcript quantification. Because photoperiods regulate the $\mathrm{CBF}$ cold-acclimation pathway and freezing tolerance in plants (Lee and Thomashow 2012), the plants were grown with a long-day (16-h) photoperiod and all samples were harvested $2 \mathrm{~h}$ before dark $(22: 00)$ as the first time point when the basal level of CBF expression was lowest (Lee and Thomashow 2012). Tissues were immediately frozen in liquid nitrogen and ground into fine powder.

Total RNA was extracted from tissues harvested at different time-points, by using the TRIzol reagent (Life Technologies, Carlsbad, CA, USA), and was subsequently stored at $-80^{\circ} \mathrm{C}$. Total RNA was quantified by using a NanoDrop ND-1000 spectrometer (Thermo Fisher Scientific). The integrity and purity of the RNA was determined based on $1 \%$ agarose gel electrophoresis and the ChemiDoc imaging system (Bio-Rad Laboratories, Hercules, CA, USA). Residual genomic DNA was removed by a treatment with RNase-free DNase I (Life Technologies) before cDNA synthesis. First-strand cDNA was synthesised from $3 \mu \mathrm{g}$ total RNA and oligo (dT) primers using a Super ScriptIII first-strand cDNA synthesis kit (Life Technologies) following the manufacturer's instructions. At least two independent cDNA synthesis reactions were performed for each sample and used as technical replicates in subsequent quantitative reverse transcription polymerase chain reaction (RT-qPCR). Synthesised cDNA was validated using MsTubulin primers with 30 cycles in a regular PCR reaction.

\section{Design of gene-specific primers}

Gene-specific primers were designed with the IDT real-time primer design tool (Integrated DNA Technologies, Coralville, IA, USA). Details of primer sequences and their melting temperatures are presented in Supplementary materials table S2. Primers were validated by using Medicago sativa genomic DNA as a template in a gradient PCR to optimise annealing temperature. PCR reactions were performed in a total volume of $20 \mu \mathrm{L}$, containing $2 \mu \mathrm{L} 10 \times$ PCR buffer, $1 \mu \mathrm{L}$ each of $10 \mu \mathrm{M}$ primers, $1 \mu \mathrm{L}$ of $2 \mathrm{~mm}$ dNTPs, $0.1 \mu \mathrm{L}$ of Taq polymerase $5 \mathrm{U}_{\mu} \mathrm{L}^{-1}$ (BioLabs, Ipswich, MA, USA) and $1 \mu \mathrm{L}$ genomic DNA ( $\left.1 \mathrm{ng} \mu \mathrm{L}^{-1}\right)$. The conditions for PCR were as follows: an initial denaturation step was performed at $94^{\circ} \mathrm{C}$ for $3 \mathrm{~min}$, followed by 35 cycles at $94^{\circ} \mathrm{C}$ for $20 \mathrm{~s}, 20 \mathrm{~s}$ at annealing temperature $\left(r=3^{\circ} \mathrm{C} \mathrm{s}^{-1}, \mathrm{G}= \pm 2.4\right)$, an extension at $72^{\circ} \mathrm{C}$ for $2 \mathrm{~min}$, and a final extension for $10 \mathrm{~min}$. All reactions were performed on a Mastercycler (Eppendorf, Hauppauge, NY, USA). Upon completing the PCR cycles, $20 \mu \mathrm{L}$ of each reaction was run on a $1 \%$ agarose gel stained with ethidium bromide, and images were visualised using a ChemiDoc (BioRad Laboratories) image analysis system.

\section{Real-time qPCR analysis}

Real-time qPCR was used to quantify transcript levels as described by Dubé et al. (2013) with some modifications. RTqPCR analysis was performed by using three independent biological replicates and two technical replicates for each biological replication. Assays were carried out in a 96-well plate (Thermo Fisher Scientific) in a fast real-time PCR system (ABI 7900 HT; Applied Biosystems, Foster City, CA, USA) using DyNAmo HS SYBR Green qPCR kits (Thermo Fisher Scientific). The $20-\mu \mathrm{L}$ reaction mixture contained $2 \mu \mathrm{L}$ firststrand cDNA and $0.5 \mu \mathrm{m}$ each of the forward and reverse primers, $10 \mu \mathrm{L} 2 \times$ Master Mix and enough water for $20 \mu \mathrm{L}$ total volume. The thermocycler program was set to: $15 \mathrm{~min}$ activation at $95^{\circ} \mathrm{C}$, followed by 40 cycles of $15 \mathrm{~s}$ at $94^{\circ} \mathrm{C}, 30 \mathrm{~s}$ at annealing temperature, $30 \mathrm{~s}$ extension at $72^{\circ} \mathrm{C}$, followed by a dissociation-curve step. The annealing temperature was set to $52.5^{\circ} \mathrm{C}$ for $C B F 1$ and $C B F 2$ and $57^{\circ} \mathrm{C}$ for $\operatorname{Cas} 15 B$ and the reference gene (MsTubulin). Twenty $\mu \mathrm{L}$ of each reaction was run on $1 \%$ agarose gels stained with ethidium bromide to check the specificity of amplification. Inter-run calibrators were included on each plate to account for plate-to-plate variation. Normalised relative expression levels were calculated using the $2^{-\Delta \Delta \mathrm{Ct}}$ or comparative $\mathrm{Ct}$ method based on the difference between the target and reference genes as described by Schmittgen and Livak (2008).

\section{Bioinformatics and phylogenetic analysis}

Nineteen MtCBF homologues were identified using the AtCBF (AtCBF1, AtCBF2, AtCBF3 and AtCBF4) protein sequences as queries against the GenBank Javi Medicago truncatula V4 release annotation database (http://www.jcvi.org/cgi-bin/ medicago/overview.cgi). The cut-off for choosing MtCBF homologues was E-value $=1 \mathrm{e}^{-30}$. Overlapping sequences were deduced. The degrees of sequence identity were determined using ALIGN on the Biology Workbench (http://workbench. sdsc.edu/). To examine the phylogenetic relationship, cluster analysis of CBF amino acid sequences in M. truncatula with previously published CBF proteins from Arabidopsis, soybean (Glycine max) and lucerne was conducted. Sequences were aligned by using ClustalW, with MEGA software version 5.1 (Tamura et al. 2011), and alignments were refined manually. The phylogenetic tree was constructed using MEGA software version 5.2.2 with the neighbour-joining method, with bootstrap probabilities calculated from 1000 replications.

\section{Data analyses}

Statistical analysis was performed with Statistix 9.0 (Analytical Software, Tallahassee, FL, USA), Excel 2010 data analysis tools pack (Microsoft, Redmond, WA, USA), and JMP 10.0.2 software (SAS Institute, Cary, NC, USA). Data were subjected to analysis of variance (ANOVA) using the linear model with completely randomised design to determine significant differences among the treatments. Tukey's HSD all-pair comparison was conducted to ascertain significant differences between treatment means $(P<0.05)$. $\mathrm{LT}_{50}$ was estimated and analysed by the method as described by Castonguay et al. (2009) and Thapa et al. (2008). 


\section{Results}

\section{Freezing tolerance}

Without cold acclimation, freezing treatment at $-5^{\circ} \mathrm{C}$ for 90 min often resulted in death of many accessions, except FR and RS. An example is shown in Fig. 1b. Control plants without freezing treatment were healthy and continued to grow (Fig. 1a). The survival rate of FR and RS was, on average,
$45 \%$ higher than frost-tolerant Caribou (Table 1). For $-10^{\circ} \mathrm{C}$ and $-12^{\circ} \mathrm{C}$ freezing treatments, respectively, non-acclimated RS showed $22 \%$ and $26 \%$ higher survival rates than Caribou, and non-acclimated FR 22\% and 45\% higher than Caribou (Table 1). Compared with the freezing-sensitive CUF variety, FR and RS showed, on average, 65-67\% higher survival rates in these freezing treatments (Table 1). The other freezingtolerant cultivar, Apica, displayed a degree of freezing
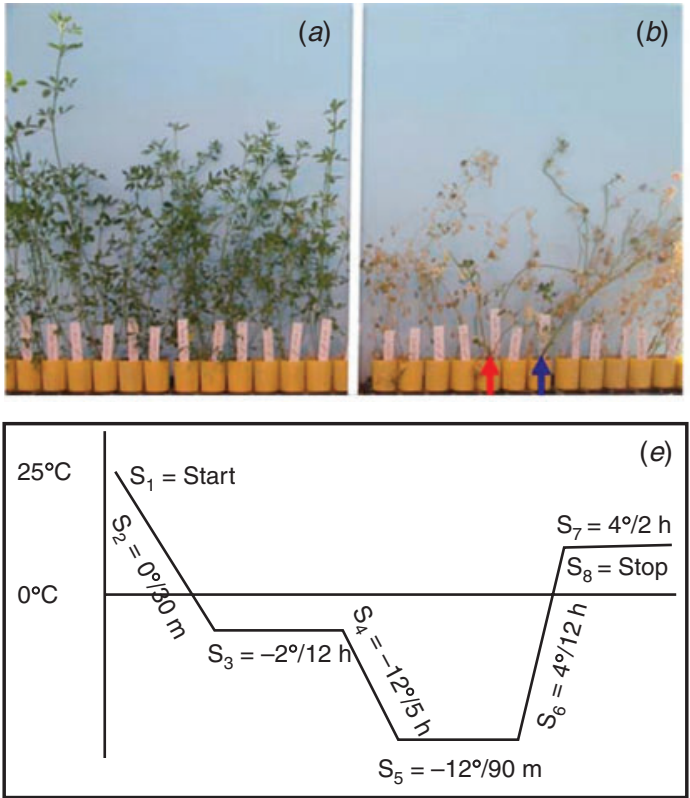
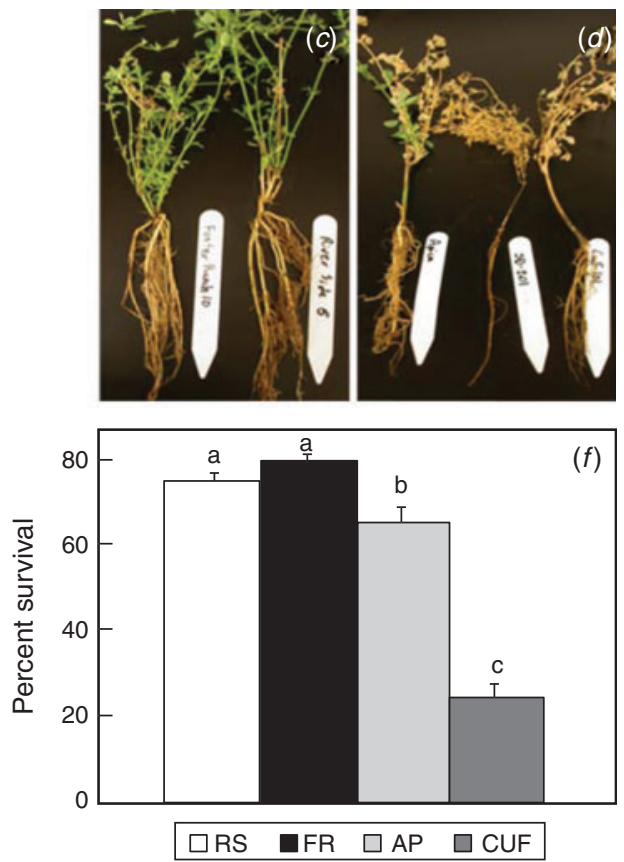

Fig. 1. Survival of lucerne seedlings following freezing: $(a)$ control plants without freezing treatment; $(b)$ River side (RS, red arrow) and Foster ranch (FR, blue arrow), which survived 7 days after $-5^{\circ} \mathrm{C}$ freezing treatment without cold acclimation; $(c)$ representative RS and FR plants 7 days after $-10^{\circ} \mathrm{C}$ freezing treatment; $(d)$ representative Apica (AP), SD-201, and CUF-101 (CUF) plants 7 days after $-10^{\circ} \mathrm{C}$ freezing treatment; $(e)$ a representative automated program used for freezing test; $(f)$ percentage survival of different germplasm sources. Data are the combination of 24 tests at three freezing temperatures $\left(-5,-10\right.$ and $\left.-12^{\circ} \mathrm{C}\right)$. Means with the same letter are not significantly different $(P>0.05, n=24)$.

Table 1. Percentage survival following freezing temperatures at $-5^{\circ} \mathrm{C},-10^{\circ} \mathrm{C}$ and $-12^{\circ} \mathrm{C}$ for the plants without cold acclimation (NA), with cold acclimation (CA) and with de-acclimation after cold acclimation (DA)

Data are mean \pm standard error. Within columns, means followed by the same letter are not significantly different $(P>0.05, n=24)$. Experiments were conducted with all germplasms at $-5^{\circ} \mathrm{C}$ but with only six selected germplasms at $-10^{\circ} \mathrm{C}$ and $-12^{\circ} \mathrm{C}$

\begin{tabular}{|c|c|c|c|c|c|c|}
\hline Germplasms & $\mathrm{NA}\left(-5^{\circ} \mathrm{C}\right)$ & $\mathrm{CA}\left(-5^{\circ} \mathrm{C}\right)$ & $\mathrm{DA}\left(-5^{\circ} \mathrm{C}\right)$ & $\mathrm{NA}\left(-10^{\circ} \mathrm{C}\right)$ & $\mathrm{CA}\left(-10^{\circ} \mathrm{C}\right)$ & $\mathrm{NA}\left(-12^{\circ} \mathrm{C}\right)$ \\
\hline A-1991 & $44 \pm 2.1 b$ & $100 \mathrm{a}$ & $44 \pm 4.3 \mathrm{c}$ & - & - & - \\
\hline Alfagraze & $56 \pm 2.7 \mathrm{a}$ & $100 \mathrm{a}$ & $67 \pm 2.0 \mathrm{a}$ & $89 \pm 3.8 \mathrm{a}$ & $78 \pm 8.0 \mathrm{bc}$ & $33 \pm 4.8 \mathrm{c}$ \\
\hline BCBB-04 & $44 \pm 3.3 b$ & $100 \mathrm{a}$ & $56 \pm 3.5 b$ & - & - & - \\
\hline CHBB-04 & $22 \pm 2.5 \mathrm{c}$ & $100 \mathrm{a}$ & $44 \pm 2.3 c$ & - & - & - \\
\hline Foster ranch & $56 \pm 2.9 a$ & $100 \mathrm{a}$ & $67 \pm 3.6 \mathrm{a}$ & $78 \pm 1.4 b$ & $100 \mathrm{a}$ & $73 \pm 3.2 \mathrm{a}$ \\
\hline River side & $56 \pm 2.3 \mathrm{a}$ & $100 \mathrm{a}$ & $67 \pm 4.0 \mathrm{a}$ & $78 \pm 1.3 b$ & $89 \pm 3.4 b$ & $54 \pm 3.0 \mathrm{~b}$ \\
\hline Wind River & $44 \pm 2.8 b$ & $100 \mathrm{a}$ & $44 \pm 1.3 c$ & - & - & - \\
\hline MT-01 & $44 \pm 2.3 b$ & $100 \mathrm{a}$ & $56 \pm 2.8 b$ & - & - & - \\
\hline DON & $11 \pm 4.3 \mathrm{~d}$ & $78 \pm 4.3 \mathrm{c}$ & $22 \pm 4.1 \mathrm{~d}$ & - & - & - \\
\hline SD-201 & $11 \pm 2.3 \mathrm{~d}$ & $89 \pm 2.1 b$ & $22 \pm 2.3 \mathrm{~d}$ & - & - & - \\
\hline Apica & $44 \pm 2.9 b$ & $100 \mathrm{a}$ & $44 \pm 2.6 c$ & $78 \pm 5.3 b$ & $67 \pm 9.2 \mathrm{c}$ & $52 \pm 4.8 b$ \\
\hline Caribou & $11 \pm 7.9 \mathrm{~d}$ & $100 \mathrm{a}$ & $44 \pm 2.3 \mathrm{c}$ & $56 \pm 6.6 \mathrm{c}$ & $89 \pm 8.0 b$ & $28 \pm 5.9 \mathrm{c}$ \\
\hline Ameristand $407 \mathrm{TQ}$ & $22 \pm 2.7 \mathrm{c}$ & $100 \mathrm{a}$ & $67 \pm 3.7 \mathrm{a}$ & - & - & - \\
\hline CUF-101 & $11 \pm 2.9 \mathrm{~d}$ & $67 \pm 2.8 \mathrm{~d}$ & $22 \pm 3.3 \mathrm{~d}$ & $11 \pm 3.1 \mathrm{~d}$ & $22 \pm 6.3 d$ & $8 \pm 2.7 d$ \\
\hline
\end{tabular}


tolerance similar to FR and RS. After cold acclimation for 10 days, the majority of plants from different germplasm sources showed nearly $100 \%$ survival rate. FR and RS, along with Alfagraze and Ameristand $47 \mathrm{TQ}$, showed the highest survival, whereas CUF was again among the germplasm with the lowest (67\%) survival rate (Table 1). Overall results after combining all of the freezing tests showed that non-acclimated FR and RS had the highest survival rates, both with $\sim 85 \%$ and $16 \%$ higher survival than CUF and Apica, respectively (Table 1, Fig. 1f). Because RS and FR showed the most consistent performance during freezing tests, they were considered the best among all of the germplasm sources tested. There were no significant differences in survival between RS and FR (Fig. 1f).

Morphological differences were evident after freezing. Both RS and FR showed strong and healthy roots after freezing stress, whereas CUF and SD-201 showed the least developed root system and dead roots (Fig. 1c, d).

\section{Leaf and shoot damage following freezing}

Differences in leaf injury of non-acclimated plants were best detected at $-3^{\circ} \mathrm{C}$, when CUF reached $50 \%$ leaf injury and RS showed $4 \%$ leaf damage (Fig. 2a). Apica leaf injury was $75 \%$ at $-4^{\circ} \mathrm{C}$, whereas injury of FR and RS was $25 \%$. At $-5^{\circ} \mathrm{C}$, leaf injury of RS and FR reached $50 \%$, whereas CUF and Apica injury approached $80 \%$ (Fig. $2 a$ ).

Leaf injury was also assessed in cold-acclimated plants. Compared with non-acclimated leaf freezing (Fig. 2a), coldacclimated leaves of all germplasm sources showed significantly less injury at the same freezing temperature (Fig. 2c,d).

Following 1 day of cold acclimation, the leaf $\mathrm{LT}_{50}$ of all germplasm decreased from the $-2.8^{\circ} \mathrm{C}$ to $-4.9^{\circ} \mathrm{C}$ range of nonacclimated plants to the $-7.8^{\circ} \mathrm{C}$ to $-11.2^{\circ} \mathrm{C}$ range of coldacclimated plants (Supplementary materials table S3). RS decreased its $\mathrm{LT}_{50}$ continuously with longer cold-acclimation and reached $-25^{\circ} \mathrm{C}$ with 7 days of cold acclimation (Fig. $2 d$ and Supplementary materials table S3). In FR and Apica, coldacclimation $>1$ day appeared to have little further effect on leaf freezing tolerance (Supplementary materials fig. S1 and table S3). Interestingly, longer cold-acclimation reduced freezing tolerance in CUF; presumably, the low temperature used in cold-acclimation may have led to some damage to CUF plants. Non-acclimated stems showed a more negative $\mathrm{LT}_{50}$ than leaves, probably because of the difference in anatomical structure of these two tissues. The ranking of freezing tolerance based on $\mathrm{LT}_{50}$ of two types of tissues was generally the same.

Shoot tissues were also tested for freezing injury at different temperatures without cold acclimation. The ranking of germplasms by shoot injury was similar to that observed by leaf injury (Fig. 2a,b). In general, shoots suffered less injury than leaves at the same temperature. The freezing temperatures that caused $50 \%$ injury for CUF, Apica, RS and FR were -5 , $-6,-10$, and $-10^{\circ} \mathrm{C}$, respectively. FR did not show much change in shoot injury at the lowest temperature tested, $-13^{\circ} \mathrm{C}$ (Fig. 2b).
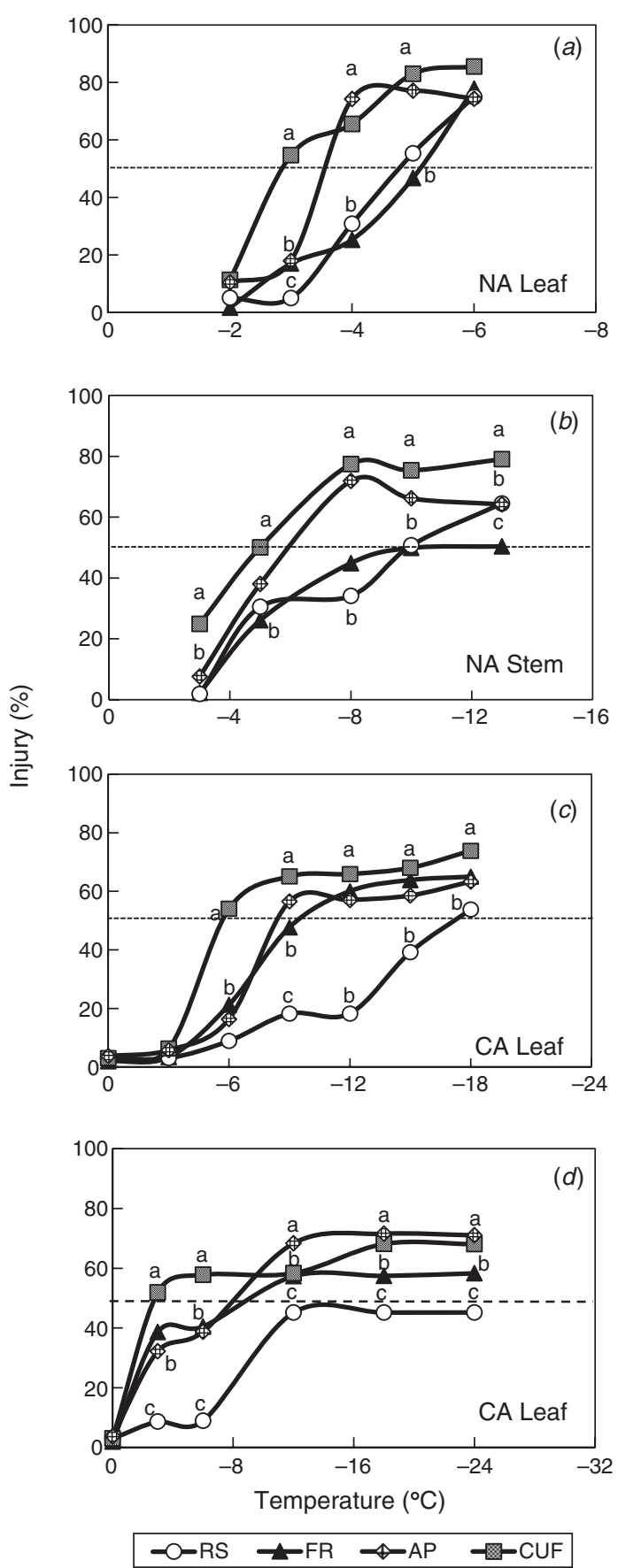

Fig. 2. Percentage electrolyte leakage (injury) at different freezing temperatures for leaves and shoots of four lucerne germplasms: Foster ranch (FR), River side (RS), CUF-101 (CUF), Apica (AP). (a) Leaf and (b) stem of non-cold-acclimated (NA) plants; leaf of plants after (c) 3 days and $(d) 7$ days of cold acclimation (CA). Among germplasm sources at the same freezing temperature, means with the same letter are not significantly different $(P>0.01, n=18)$.

\section{Soluble sugar contents and RWC}

Non-acclimated RS and CUF shoots accumulated 25\% more soluble sugars than those of FR and Apica (Fig. 3a). 
A 24-h cold treatment at $4^{\circ} \mathrm{C}$ caused a $26 \%$ reduction in soluble-sugar accumulation compared with tissues at $0 \mathrm{~h}$ in all genotypes except Apica, which showed a 10\% increase compared with tissues at $0 \mathrm{~h}$. Genotype CUF showed a major reduction, decreasing from 22 to $11 \mathrm{mg} \mathrm{g}^{-1} \mathrm{DW}$. After $72 \mathrm{~h}$ of cold treatment, RS showed a significant increase $(\sim 40 \%)$ in solublesugar accumulation over the 24-h treatment, reaching a level slightly higher than at $0 \mathrm{~h}$. On the other hand, Apica showed a significant decrease in sugar content from 24 to $72 \mathrm{~h}$, reaching slightly lower level than that at $0 \mathrm{~h}$. Soluble-sugar content of FR fluctuated from 2 to $3 \mathrm{mg} \mathrm{g}^{-1} \mathrm{DW}$ during the experiment.

Four germplasms also showed differences in RWC before and after cold treatment (Fig. 3b). RS and CUP showed the highest RWC before cold treatment. CUF showed $>50 \%$ reduction in RWC after cold treatment and had the lowest RWC among the four lucerne germplasms. RS and Apica showed relatively stable RWC before and after treatment. FR showed a reduction of nearly $40 \%$ in RWC after $24 \mathrm{~h}$ of cold treatment but recovered RWC at $72 \mathrm{~h}$ after cold treatment.

\section{Cold-responsive gene expression}

Transcript levels of $M s C B F 1$ and $M s C B F 2$ were enhanced by cold treatment in lucerne plants in a previous study (Pennycooke et al. 2008), and their transcript levels were examined here. At $2 \mathrm{~h}$ after cold treatment, the transcript level of $M s C B F 1$ increased 18-fold for RS and 25-fold in FR. However, by $24 \mathrm{~h}$ after cold treatment, the transcript level decreased to its original level in RS and to 8-fold in FR. Apica showed a slight increase in $M s C B F 1$ transcripts at both 2 and $24 \mathrm{~h}$ after cold
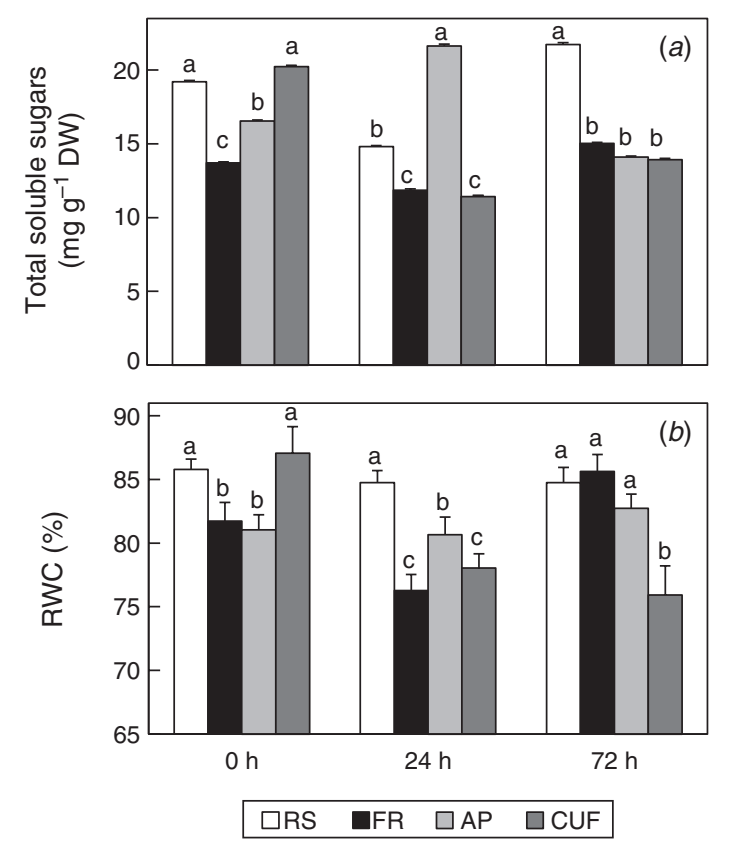

Fig. 3. (a) Total soluble sugar content and (b) relative water content in shoots of River side (RS), Foster ranch (FR), Apica (AP) and CUF-101 (CUF) following 0,24 and $72 \mathrm{~h}$ cold treatment. Among germplasm sources at the same time point, means with the same letter are not significantly different $(P>0.01, n=24)$. treatment. CUF showed no induction in $M s C B F 1$ transcript after cold treatment (Fig. 4a).

Cold induction caused a significant increase in the $M s C B F 2$ transcript level of Apica, RS and CUF (Fig. 4b). Within $2 \mathrm{~h}$ of cold induction, transcript levels of $M s C B F 2$ were elevated 12- and 16-fold for RS and Apica, respectively. However, transcript levels of both genotypes declined $24 \mathrm{~h}$ after cold treatment to 4-8-fold that observed before cold treatment. CUF showed a 4-fold increase in $M S C B F 2$ transcript level at $2 \mathrm{~h}$, but returned to the original level at $24 \mathrm{~h}$ after cold treatment. FR showed no change in $M S C B F 2$ transcript level after cold treatment (Fig. 4b).

Protein-sequence analysis identified 19 members in M. truncatula that were similar to Arabidopsis CBFs. The $M$. truncatula genome was used because the lucerne genome sequence is not yet available. The $M$. truncatula CBFs are roughly grouped into two large clusters, and $M S C B F 1$ and $M S C B F 2$ happen to be representative of these two clusters
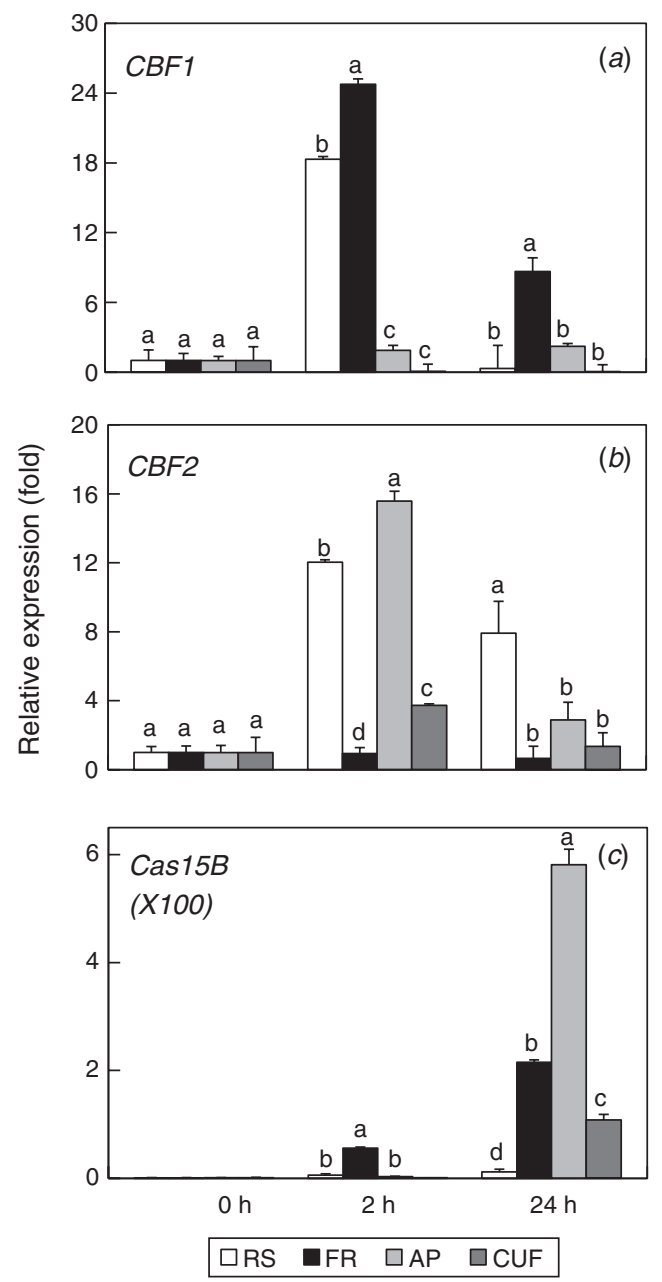

Fig. 4. Relative transcript levels of cold-responsive genes in different germplasm sources before and after cold induction: River side (RS), Foster ranch (FR), Apica (AP), CUF-101 (CUF). Among germplasm sources at the same time point, means with the same letter are not significantly different $(P>0.01, n=6)$. 
(Fig. 5). Phylogenetic analysis also suggested that most Medicago CBFs are likely to be duplicated after divergence of Arabidopsis and Medicago, because Arabidopsis CBF1-4 formed one cluster, whereas Medicago CBFs formed their own clusters. On the other hand, three of the soybean CBF-like proteins, $\mathrm{GmCBF} 1, \mathrm{GmCBF} 2$, and $\mathrm{GmCBF} 3$, clustered with various Medicago $\mathrm{CBFs}$, suggesting that duplication of these genes occurred before divergence of soybean and Medicago. Soybean DREB1-3 formed an independent cluster, whereas 13 Medicago CBFs (MtCBF2-3, 5-12, 14 and 16) formed a cluster without soybean $\mathrm{CBFs}$, suggesting that these genes duplicated after divergence of these two legume plants. AtCBF5 was distantly related to other AtCBFs and was thus not clustered with other CBFs. An AtCBF5-like sequence was identified in Medicago but not in the soybean genome (Fig. 5).

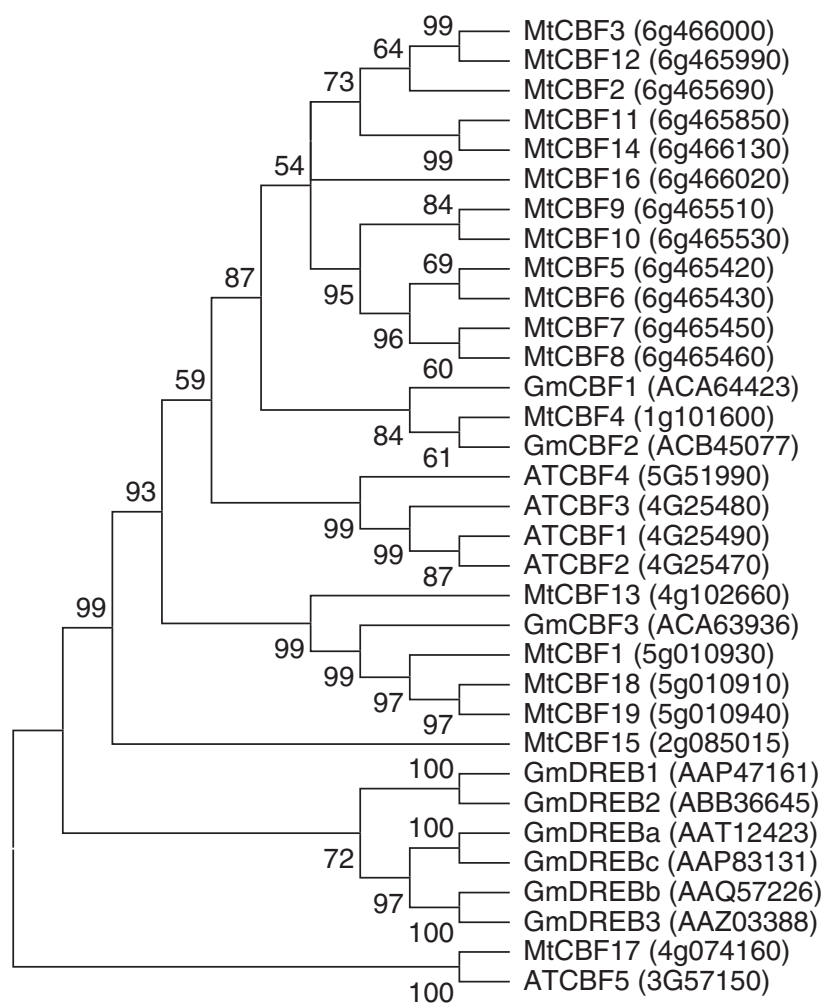

Fig. 5. Bootstrap consensus neighbour-joining circle tree of $\mathrm{CBF}$ proteins from Arabidopsis, Medicago truncatula, and soybean (Glycine max). The numbers shown next to the branches are the bootstrap probabilities from 1000 replications. Arabidopsis sequences include: ATCBF1 (4G25490), ATCBF2 (4G25470), ATCBF3 (4G25480), ATCBF4 (5G51990), ATCBF5 (3G57150). Medicago truncatula sequences include: MtCBF1 (5g010930), MtCBF2 (6g465690), MtCBF3 (6g466000), MtCBF4 (1g101600), MtCBF5 (6g465420), MtCBF6 (6g465430), MtCBF7 (6g465450), MtCBF8 (6g465460), MtCBF9 (6g465510), MtCBF10 (6g465530), MtCBF11 (6g465850), MtCBF12 (6g465990), MtCBF13 (4g102660), MtCBF14 (6g466130), MtCBF15 (2g085015), MtCBF16 (6g466020), MtCBF17 (4g074160), MtCBF18 (5g010910), MtCBF19 (5g010940). Soybean sequences include: GmCBF1 (ACA64423), GmCBF2 (ACB45077), GmCBF3 (ACA63936), GmDREBa (AAT12423), GmDREBb (AAQ57226), GmDREBc (AAP83131), GmDREB1 (AAP47161), GmDREB2 (ABB36645), GmDREB3 (AAZ03388).
For FR, the Cas 15B transcript level increased 60-fold within $2 \mathrm{~h}$ of transfer to low temperature and continued to increase 210 -fold over the next $24 \mathrm{~h}$ (Fig. 4c). A significant increase in Cas 15B levels in Apica and CUF was also observed $24 \mathrm{~h}$ after cold treatment, with Apica reaching 600-fold induction and CUF 55-fold. RS did not show any change in Cas $15 B$ transcript level under cold induction.

\section{Discussion}

\section{Superior freezing tolerance of $R S$ and FR}

We identified RS and FR as showing the highest freezing tolerance based on survival rate with or without cold acclimation. This is supported by multiple freezing tests, reflecting a more consistent performance of these germplasm lines under freezing stress, the results of freezing-survival test being highly variable, as indicated in Table 1. Alfagraze, a commercial cultivar developed in the Midwest, also showed excellent freezing tolerance. This is expected because Alfagraze has been shown to have freezing tolerance based on winter survival in field conditions (Schwab et al. 1996a). RS and FR also showed better survival than Apica and Caribou, two cultivars developed with greater freezing tolerance after cold acclimation of mature plants in Canada (Castonguay et al. 2009). Two different mechanisms are likely in play - dormancy and freezing tolerance - and both are correlated with survival. Both germplasms showed better winter survival and freezing tolerance under a control treatment environment. However, further field dormancy tests may confirm their winter survival rather than tolerance to abrupt freezing.

There are indications in the literature that freezing tolerance is directly linked to survival rate and the possibilities of identifying cold-tolerant germplasms based on survival test (Waldron et al. 1998; Weishaar et al. 2005; Castonguay et al. 2009). An ion-leakage test performed on leaf tissue was efficient for determining freezing tolerance in the two $M$. truncatula genotypes (Thapa et al. 2008). This is consistent with the results of leaf and stem electrolyte-leakage analysis in this study. RS and FR require lower freezing temperatures to reach the same leaf and stem electrolyte leakage as Apica, suggesting that RS and FR may indeed be more freezing-tolerant. Their greater freezing tolerance may be a consequence of their adaption to the harsh winter conditions at the Grand River National Grassland during the naturalisation process.

\section{Physiological responses to cold treatment}

Germplasms RS and FR showed greater freezing tolerance without lengthy cold acclimation, suggesting that their initial physiological process or status differs from that of CUF. Owing to its potentially important role in freezing tolerance, we examined whether the total soluble sugar content in RS and FR differs from that in CUF. The fact that the initial total soluble sugar content was similar in RS and CUF before cold treatment $(0 \mathrm{~h})$ and in FR and CUF after $24 \mathrm{~h}$ of cold treatment suggests that the difference in total soluble sugar may not be the key factor determining the difference in freezing tolerance. This is further supported by the fact that the amount of total soluble sugar in FR, Apica and CUF is the same after $72 \mathrm{~h}$ of cold 
acclimation, but FR and Apica are freezing-tolerant and CUF is freezing-sensitive.

A major role of total soluble sugar content is believed to be on osmotican to adjust RWC. Our results tend to support this, there being a close relationship between RWC and the sugar content (Fig. 3). For example, higher sugar content is associated with higher RWC in different lucerne germplasms at $0 \mathrm{~h}$. In addition, CUF showed a decrease in sugar content after cold treatment, and RWC decreased accordingly. However, Apica showed the highest total soluble sugar content, whereas its RWC was $10 \%$ lower than of RS and CUF. In addition, RS showed the highest total soluble sugar at $72 \mathrm{~h}$ after cold treatment, although its RWC was the same as those of FR and Apica. The results suggest that other factors in these germplasms may contribute to the change in RWC, and that the significance of the total soluble sugar in controlling RWC varies among germplasms and environmental conditions.

Germplasms RS and FR showed similar survival following freezing treatment (Fig. 1f) and leaf and shoot injury without cold acclimation (Fig. 2a, b); however, their freezing tolerance differed after cold acclimation (Fig. 2c), suggesting that they may have employed different mechanisms in freezing tolerance. After a 24-h cold treatment, changes in the total soluble sugar and RWC between RS and FR were very similar, although RS generally showed a greater amount of soluble sugar and RWC, further supporting the hypothesis that other mechanisms may have contributed to the difference in freezing tolerance.

Cell membrane integrity is critical to freezing injury in plants. Numerous factors are involved in loss of membrane integrity at freezing temperature, such as expansion-induced lysis, damage caused by ROS species, and protein denaturation (Thomashow 1999). Cold acclimation may have induced different metabolic changes in RS and FR, which lead to differences in membrane fluidity and in protecting the membrane from freeze-induced dehydration shock (Graham and Patterson 1982).

\section{Expression of cold-responsive genes}

Our results demonstrated that the $C B F$ genes are highly inducible by cold temperature. The fact that the $C B F$ genes are much more highly upregulated in RS, FR and Apica than in CUF suggests that these $C B F$ s play an important role in lucerne freezing tolerance. RS plants, which were more freezing-tolerant after cold acclimation than FR plants, demonstrated induction in both $M s C B F 1$ and $M s C B F 2$ genes. FR showed induction of only $M S C B F 1$, further suggesting the importance of the $C B F$ gene family. Our bioinformatics analysis identified $19 C B F$-like genes in M. truncatula (Fig. 5). Analysis of expression of other $C B F$ genes in lucerne under cold conditions may provide further insights into the importance of $C B F$ genes in lucerne freezing tolerance.

Pennycooke et al. (2008) and Mohapatra et al. (1989) reported that the transcript levels of cold-acclimated specific $(C A S)$ genes, such as Cas15B, were associated with lowtemperature tolerance levels of individual cultivars. Our results confirmed the cold-inducible nature of Cas $15 B$ gene expression (Mohapatra et al. 1989; Pennycooke et al. 2008). More importantly, FR showed earlier induction of Cas $15 B$ expression than Apica, whereas Apica showed the highest induction at $24 \mathrm{~h}$. The fact that CUF also showed a significant induction of the Cas $15 B$ gene and RS did not show a significant induction under cold suggests that Cas $15 B$ is only one of multiple potential molecular markers for cold tolerance in lucerne and may not be the best. The results, together with the expression pattern of $C B F$ genes in different germplasm sources, support the notion that freezing tolerance in lucerne is a complex trait and that identification and combination of different mechanisms can lead to improvement of freezing tolerance in the species.

Overall, these findings support the hypothesis that Grand River National Grassland adapted germplasms RS and FR possess different physiological and molecular mechanisms that may greatly improve their freezing tolerance.

\section{Author contribution}

R.A., A.F., A.B., and Y.W. designed the experiments. R. A. performed the experiments. R.A. and Y.W. conducted data analysis. R.A., A.F., A.B., I.M., M.P. and Y.W. prepared the manuscript.

\section{Acknowledgements}

This research work was supported by South Dakota Agricultural Experiment Station at South Dakota State University and by the USDA-ARS. We are grateful to Ms Praveena Kanchupati for her generous help and to Dr Yves Castonguay (AAFC, Canada) for providing Apica and Caribou seeds.

\section{References}

Anchordoguy TJ, Rudolph AS, Carpenter JF, Crowe JH (1987) Modes of interaction of cryoprotectants with membrane phospholipids during freezing. Cryobiology 24, 324-331. doi:10.1016/0011-2240(87)90036-8

Anower MR, Mott IW, Peel MD, Wu Y (2013) Characterization of physiological responses of two alfalfa half-sib families with improved salt tolerance. Plant Physiology and Biochemistry 71, 103-111. doi:10.10 16/j.plaphy.2013.06.026

Arias NS, Bucci SJ, Scholz FG, Goldstein G (2015) Freezing avoidance by supercooling in Olea europaea cultivars: the role of apoplastic water, solute content and cell wall rigidity. Plant, Cell \& Environment 38, 2061-2070. doi:10.1111/pce.12529

Barrs H, Weatherley P (1962) A re-examination of the relative turgidity technique for estimating water deficits in leaves. Australian Journal of Biological Sciences 15, 413-428.

Brouwer DJ, Duke SH, Osborn TC (2000) Mapping genetic factors associated with winter hardiness, fall growth, and freezing injury in autotetraploid alfalfa. Crop Science 40, 1387-1396. doi:10.2135/cropsci 2000.4051387x

Burr KE, Tinus RW, Wallner SJ, King RM (1990) Comparison of three cold hardiness tests for conifer seedlings. Tree Physiology 6, 351-369. doi:10. 1093/treephys/6.4.351

Castonguay Y, Laberge S, Brummer EC, Volenec JJ (2006) Alfalfa winter hardiness: a research retrospective and integrated perspective. In 'Advances in agronomy'. Vol. 90. (Ed. LS Donald) pp. 203-265. (Academic Press: Cambridge, MA, USA)

Castonguay Y, Michaud R, Nadeau P, Bertrand A (2009) An indoor screening method for improvement of freezing tolerance in alfalfa. Crop Science 49, 809-818. doi:10.2135/cropsci2008.09.0539

Castonguay Y, Michaud J, Dubé M-P (2015) Reference genes for RT-qPCR analysis of environmentally and developmentally regulated gene expression in alfalfa. American Journal of Plant Sciences 6, 132-143. doi:10.4236/ajps.2015.61015 
Chen J, Han G, Shang C, Li J, Zhang H, Liu F, Wang J, Liu H, Zhang Y (2015) Proteomic analyses reveal differences in cold acclimation mechanisms in freezing-tolerant and freezing-sensitive cultivars of alfalfa. Frontiers in Plant Science 6, 105. doi:10.3389/fpls.2015.00105

Chinnusamy V, Zhu J, Zhu J-K (2007) Cold stress regulation of gene expression in plants. Trends in Plant Science 12, 444 451. doi:10.1016/ j.tplants.2007.07.002

Dubé MP, Castonguay Y, Cloutier J, Michaud J, Bertrand A (2013) Characterization of two novel cold-inducible K3 dehydrin genes from alfalfa (Medicago sativa spp. sativa L.). Theoretical and Applied Genetics 126, 823-835.

Duca M (2015) Physiology of plant resistance to unfavorable environmental factors. In 'Plant physiology'. pp. 271-308. (Springer: Dordrecht, The Netherlands)

Farooq M, Aziz T, Wahid A, Lee D-J, Siddique KH (2009) Chilling tolerance in maize: agronomic and physiological approaches. Crop \& Pasture Science 60, 501-516. doi:10.1071/CP08427

Fowler S, Thomashow MF (2002) Arabidopsis transcriptome profiling indicates that multiple regulatory pathways are activated during cold acclimation in addition to the CBF cold response pathway. The Plant Cell 14, 1675-1690. doi: $10.1105 /$ tpc.003483

Gilmour SJ, Sebolt AM, Salazar MP, Everard JD, Thomashow MF (2000) Overexpression of the Arabidopsis CBF3 transcriptional activator mimics multiple biochemical changes associated with cold acclimation. Plant Physiology 124, 1854-1865. doi:10.1104/pp.124.4.1854

Graham D, Patterson BD (1982) Responses of plants to low, nonfreezing temperatures: proteins, metabolism, and acclimation. Annual Review of Plant Physiology 33, 347-372. doi:10.1146/annurev.pp.33.060182.00 2023

Guy CL (1990) Cold acclimation and freezing stress tolerance: role of protein metabolism. Annual Review of Plant Biology 41, 187-223. doi:10.1146/annurev.pp.41.060190.001155

Jaglo-Ottosen KR, Gilmour SJ, Zarka DG, Schabenberger O, Thomashow MF (1998) Arabidopsis CBF1 overexpression induces COR genes and enhances freezing tolerance. Science 280, 104-106. doi:10.1126/ science. 280.5360 .104

Lee C-M, Thomashow MF (2012) Photoperiodic regulation of the C-repeat binding factor (CBF) cold acclimation pathway and freezing tolerance in Arabidopsis thaliana. Proceedings of the National Academy of Sciences of the United States of America 109, 15054-15059. doi:10.1073/pnas. 1211295109

Levitt J (1980) Responses of plants to environmental stresses. In 'Physiological ecology: chilling, freezing, and high temperature stresses'. Vol. 1. (Ed. TT Kozlowski) pp. 248-283. (Academic Press: Cambridge, MA, USA)

Lizhen N, Hongkui L, Jie S, Jing Y, Yongzhi L (2015) A study on cold tolerance transgenic alfalfa (Medicago sativa $\mathrm{L}$.) with the AmDHN gene. In 'Molecular breeding of forage and turf'. pp. 173-181. (Springer: Dordrecht, The Netherlands)

Maruyama K, Sakuma Y, Kasuga M, Ito Y, Seki M, Goda H, Shimada Y, Yoshida S, Shinozaki K, Yamaguchi-Shinozaki K (2004) Identification of cold-inducible downstream genes of the Arabidopsis DREB1A/CBF3 transcriptional factor using two microarray systems. The Plant Journal 38, 982-993. doi:10.1111/j.1365-313X.2004.02100.x

Mattsson A (1997) Predicting field performance using seedling quality assessment. New Forests 13, 227-252. doi:10.1023/A:1006590409595

McKenzie J, Paquin R, Duke SH (1988) Cold and heat tolerance. In 'Alfalfa and alfalfa improvement'. Agronomy Monograph 29. (Eds AA Hanson, DK Barnes, RR Hill) pp. 259-302. (ASA, CSSA and SSSA: Madison, WI, USA)

McKersie BD, Bowley SR, Harjanto E, Leprince O (1996) Water-deficit tolerance and field performance of transgenic alfalfa overexpressing superoxide dismutase. Plant Physiology 111, 1177-1181.
Mohapatra SS, Wolfraim L, Poole RJ, Dhindsa RS (1989) Molecular cloning and relationship to freezing tolerance of cold-acclimationspecific genes of alfalfa. Plant Physiology 89, 375-380. doi:10.1104/ pp.89.1.375

Monroy AF, Dhindsa RS (1995) Low-temperature signal transduction: induction of cold acclimation-specific genes of alfalfa by calcium at $25^{\circ} \mathrm{C}$. The Plant Cell 7, 321-331.

Monroy AF, Castonguay Y, Laberge S, Sarhan F, Vezina LP, Dhindsa RS (1993) A new cold-induced alfalfa gene is associated with enhanced hardening at subzero temperature. Plant Physiology 102, 873-879. doi:10.1104/pp.102.3.873

Park S, Lee CM, Doherty CJ, Gilmour SJ, Kim Y, Thomashow MF (2015) Regulation of the Arabidopsis CBF regulon by a complex lowtemperature regulatory network. The Plant Journal 82, 193-207. doi: $10.1111 /$ tpj. 12796

Pennycooke JC, Cheng H, Stockinger EJ (2008) Comparative genomic sequence and expression analyses of Medicago truncatula and alfalfa subspecies falcata COLD-ACCLIMATION-SPECIFIC genes. Plant Physiology 146, 1242-1254. doi:10.1104/pp.107.108779

Rocher S, Jean M, Castonguay Y, Belzile F (2015) Validation of genotyping-by-sequencing analysis in populations of tetraploid alfalfa by 454 sequencing. PLoS One 10, e0131918. doi:10.1371/journal.pone. 0131918

Schmittgen TD, Livak KJ (2008) Analyzing real-time PCR data by the comparative CT method. Nature Protocols 3, 1101-1108.

Schwab P, Barnes D, Sheaffer C (1996a) The relationship between field winter injury and fall growth score for 251 alfalfa cultivars. Crop Science 36, 418-426. doi:10.2135/cropsci1996.0011183X00360002 0034x

Schwab PM, Barnes DK, Sheaffer CC, Li PH (1996b) Factors affecting a laboratory evaluation of alfalfa cold tolerance. Crop Science $\mathbf{3 6}$, 318-324. doi:10.2135/cropsci1996.0011183X003600020018x

Sheaffer C, Lake A, BL Buchanan-Smith JG, McCaughey P (Ed.) (1997) Legumes in cropping systems: approaches in Midwest United States and Southern Australia. In 'Proceedings of the XVIII International Grassland Congress'. Winnipeg, MB, Canada. (International Grassland Congress)

Sulc RM, Albrecht KA, Duke SH (1991) Leakage of intracellular substances as an indicator of freezing injury in alfalfa. Crop Science 31, 430-435. doi:10.2135/cropsci1991.0011183X003100020041x

Tamura K, Peterson D, Peterson N, Stecher G, Nei M, Kumar S (2011) MEGA5: molecular evolutionary genetics analysis using maximum likelihood, evolutionary distance, and maximum parsimony methods. Molecular Biology and Evolution 28, 2731-2739. doi:10.1093/molbev/ msr121

Tarkowski ŁP, Van den Ende W (2015) Cold tolerance triggered by soluble sugars: a multifaceted countermeasure. Frontiers in Plant Science 6, 203. doi:10.3389/fpls.2015.00203

Thapa B, Arora R, Knapp AD (2008) Applying freezing test to quantify cold acclimation in Medicago truncatula. Journal of the American Society for Horticultural Science 133, 1-2.

Thomashow MF (1998) Role of cold-responsive genes in plant freezing tolerance. Plant Physiology 118, 1-8. doi:10.1104/pp.118.1.1

Thomashow MF (1999) Plant cold acclimation: freezing tolerance genes and regulatory mechanisms. Annual Review of Plant Biology 50, 571-599. doi:10.1146/annurev.arplant.50.1.571

Thomashow MF (2001) So what's new in the field of plant cold acclimation? Lots! Plant Physiology 125, 89-93. doi:10.1104/pp.125. 1.89

Waldron B, Ehlke N, Vellekson D, White D (1998) Controlled freezing as an indirect selection method for field winterhardiness in turf-type perennial ryegrass. Crop Science 38, 811-816. doi:10.2135/cropsci1998. 0011183X003800030032x 
Weishaar MA, Brummer EC, Volenec JJ, Moore KJ, Cunningham S (2005) Improving winter hardiness in nondormant alfalfa germplasm. Crop Science 45, 60-65. doi:10.2135/cropsci2005.0060

Zhang S, Shi Y, Cheng N, Du H, Fan W, Wang C (2015) De novo characterization of fall dormant and nondormant alfalfa (Medicago sativa L.) leaf transcriptome and identification of candidate genes related to fall dormancy. PLoS One 10, e0122170. doi:10.1371/journal. pone. 0122170
Zhao C, Lang Z, Zhu J-K (2015) Cold responsive gene transcription becomes more complex. Trends in Plant Science 20, 466-468. doi:10.1016/j.tplants.2015.06.001

Zuther E, Juszczak I, Lee YP, Baier M, Hincha DK (2015) Time-dependent deacclimation after cold acclimation in Arabidopsis thaliana accessions. Scientific Reports 5, 12199. doi:10.1038/srep12199 